\title{
Effect of grain mass properties on the processes of extraction and hydration
}

\author{
Tetiana Yaniuk, Tetiana Trakhalo, Halyna Liashko, \\ Olena Galynska, Nataliia Hriunvald
}

National University of Food Technologies, Kyiv, Ukraine

Keywords:

Grain

Hydration

Extraction

Hydromodul

Grinding

\section{Article history:}

Received

01.05.2021

Received in revised form

12.09.2021

Accepted

30.12.2021

Corresponding author:

Tetiana Yaniuk

E-mail:

ytata13@ukr.net

DOI:

$10.24263 / 2304-$

974X-2021-10-

4-13

\section{Abstract}

Introduction. The aim of the present research was to determine the quantity of non-freezing water in the mixtures of flax seeds where carbohydrates are mainly heteropolysaccharides and in amaranth, oats and rice mixtures where carbohydrates are mainly monopolysaccharides.

Materials and methods. Water and whey were chosen as solvents. Extracts were prepared by solvent addition to hydrated raw materials with a moisture content, \%: flax seeds, 6.3; amaranth seeds, 9.4; oats. 10.5, and rice, 11.8. The state of water in the mixtures at different stages of hydration was studied by the method of low-temperature canning calorimetry.

Results and discussion. In samples with water as a solvent the total moisture content is $92.4 \%$, bound moisture is $3.77 \%$, and in samples with whey as a solvent it is $83.49 \%$ and $13.44 \%$, respectively. Whereas after the first stage of processing (percolation) these indicators were as follows: total moisture was $99.91 \%$ and bound moisture was $0.09 \%$. Thus, the mechanical treatment that was used to intensify the extraction and hydration processes has provided redistribution of the fractional composition of moisture increasing the amount of the bound water. When using whey as a solvent, this redistribution is even more defined. This process is influenced by the $\mathrm{pH}$ of the environment changed by the whey, but the main factor is carbohydrates, the amount of which in the whey is up to $6.0 \%$.

The weight of freezing water in the treated sample of amaranth suspensions increased to $2.56 \mathrm{mg}$ from the weight of $2.16 \mathrm{mg}$ in the untreated sample. And the mass of bound water in the treated sample was $0.52 \mathrm{mg}$, while in the untreated sample was $0.14 \mathrm{mg}$. In the oat suspensions samples both the initial and treated peaks were almost the same; the shift towards low temperatures was not observed. In the treated sample of rice suspensions, a second small peak occurred and the total area towards the untreated sample increased. It means that the mass of freezing water in rice increased to $2.59 \mathrm{mg}$ from $2.28 \mathrm{mg}$ after treatment in the untreated sample, at the same time, the mass of bound water increased to $0.28 \mathrm{mg}$ from 0.06 $\mathrm{mg}$ in the untreated sample. Percentage of the total moisture in the suspension of amaranth seeds, the amount of freezing water after treatment decreased by $10.84 \%$, in oat suspension by $4.69 \%$, in rice suspension by $7.4 \%$. At the same time, the amount of bound water increased by $10.94 \%$ for the suspension of amaranth seeds, for the suspension of oats by $4.67 \%$, and for the suspension of rice by $7.4 \%$.

The presence of salt or acid also effects on the completeness and speed of the swelling and wet absorption processes, as well as on redistribution of water in the grinded grain.

Conclusions. The mechanical treatment used to intensify the processes of extraction and hydration ensured the redistribution of the fractional composition of moisture in the crushed grain raw materials, increasing the percentage of bound water. 


\section{Introduction}

The role of grain products is often analyzed in the scientific literature regarding the level of consumption and nutritional value (Papanikolaou and Fulgoni, 2017; 2018). Grain products contain dietary fiber (Papanikolaou and Fulgoni, 2017), B vitamins (including thiamine, niacin, riboflavin), vitamin $\mathrm{E}$ and minerals (calcium, magnesium, potassium, phosphorus, iron, sodium, manganese and zinc) (O’Neil et al., 2010).

An important task of the food preparation is the use of gentle modes of processing of raw materials for the purpose of the maximum preservation of valuable nutrients as well as the use of advanced methods of its preparation for increasing the content of biologically active components (Bazhai-Zhezherun et al., 2017).

Cereal-based beverages have a huge potential as functional food. They can serve as carriers for a range of functional compounds, for example antioxidants, dietary fiber, minerals, probiotics, and vitamins. However, more research is needed to fully understand the impact of some of the functional components (e.g. antioxidants) present in cereal-based beverages (Kreisz et al., 2008).

In the current era, the customers are very demanding for an innovative nutritious food with enhanced functionality. Diet containing healthy foods and beverages plays a major role in avoiding and healing of chronic dreadful diseases eventually improving human health. Nutraceuticals are part of food ingredient or source from food products/by-products leading to offer additional strength and beneficial effects. The research on functional constituent has shown promising results for the utilization of such components in food commodities eventually results value addition for manufacturer and healthy for consumers.

Nowadays nutraceuticals are the major components that are being incorporated in novel drug formulations, healthy foods, and food added mixtures. There is slight vagueness among the terms functional foods and nutraceuticals. When plant extract /bioactives/ phytochemicals are used as food additives it is generally termed as functional food, but when the same is consumed in the form of pill/capsule the term nutraceutical is used. Functional beverage, the fastest growing area, is the subsection of functional foods along with nonalcoholic beverages. Therefore, the manufacturing and utilization of functional beverages has achieved much impact. These include processed beverages with health-promoting additives such as dietary fibers, minerals, vitamin-rich beverages, probiotic-rich fermented beverages, vitamin D supplemented milk, vitamins A-, C-, E-enriched nonalcoholic beverages, etc. In the current era beverages are an ideal delivery vehicle for protein, antioxidants, minerals, vitamins, fibers, $\omega-3$ fatty acids, natural plant extracts, prebiotics, probiotics, and other functional ingredients due to the convenience and prospect to fulfill the customers demand. Low-temperature preservation facilitates sustaining these nutrients in active condition. Nonetheless, special apprehension has been boosted up over their security in most cases. The objective of this review includes promising trends of usage of functional beverages with special attention on commercial beverages and their health benefits vs. their health implications (Ghoshal and Kansal, 2019).

Processing is a prerequisite for the use of cereal grains in food. Processing involves the use of one or more-unit operations, involving application of mechanical or thermal energy, hydration and often activation of the endogenous biological enzymatic system of the grains. These operations induce various macroscopic to molecular level changes in the grain components, hence affecting the nutritional, technological and sensory properties of the products (Poutanen et al., 2014; Rosa-Sibakov et al., 2015).

While cereal processing (milling, extrusion, and baking) is designed to create intentional changes in dietary fiber, unintentional changes due to oxidation and enzymatic hydrolysis by endogenous or microbial enzymes can also occur. Both intentional and unintentional changes in solubility, extractability and physicochemical properties of dietary fiber and restructuring of the 
grain matrix can either unlock or hamper the physiological and technological value of dietary fiber (Smith et al., 2020; Seal et al., 2021).

One such way of processing vegetable raw materials is extraction. This process makes it possible to extract biologically active substances from raw materials. The advantages of this method are as follows: short duration of the extraction process, usability, and mild conditions preventing the destruction of raw material, high efficiency and ability to be combined with other methods (Gulevich et al., 2009).

There are two stages in the extraction process: swelling of the raw material with a solution of the constituent components of the grinded grain particles and the extraction process, when the particles are transported from cell membranes and capillaries into the mass of the solvent. As a rule, the swelling of raw materials takes about 5-6 hours and even more.

The use some methods of preparation and processing of raw materials, such as infrared and ultraviolet radiation, ultrasonic action, the use of rotary pulse devices and dispersants can accelerate the extraction process by 5-6 times and significantly increase the yield of extractives to $20-40 \%$.

The extract is a concentrated substrate removed from the grain. There are liquid extracts, viscous masses with a moisture content not more than $25 \%$, dry extracts with a moisture content not more than $5 \%$.

The purpose of this research is to obtain experimental results determining the amount of antifreeze water in mixtures of flax seeds where carbohydrates are mainly heteropolysaccharides, in amaranth, oats, rice mixtures where carbohydrates are represented mainly by monopolysaccharides.

\section{Materials and methods}

\section{Materials}

\section{Sample preparation: grain and seed extracts}

The following samples were selected as materials for the research:

a. Flax seed extracts with water and whey:

1 - sample after mechanical treatment, whey as an extractant (upper layer),

2 - sample after mechanical treatment, whey as an extractant (suspension),

3 - sample after mechanical treatment, water (upper layer);

b. Extracts of amaranth seeds with water:

4 - suspension of amaranth in water (initial sample),

5 - suspension of amaranth in water (mechanical treatment);

c. Oat grain extracts with water:

6 - oat suspension in water (initial sample),

7 - oat suspension in water (mechanical treatment);

d. Rice grain extracts with water

8 - suspension of rice in water (initial sample),

9 - suspension of rice in water (mechanical treatment).

Extracts were prepared by addition of water or whey to the raw material in a ratio of 5: 1 at a temperature of $25^{\circ} \mathrm{C}$. 


\section{Methods}

\section{Mass fraction of moisture}

The mass fraction of moisture in the experimental samples was determined by the method of drying to constant weight. Preparation of samples. To determine the mass fraction of moisture from the average grain sample allocate about $30 \mathrm{~g}$, grind to standard size, so that when sifting through a wire sieve with a hole size of $0.8 \mathrm{~mm}$ passed oats - not less than $30 \%$, rice and amaranth $-50 \%$ of total grinding. The ground grain is collected in a glass jar with a ground lid and mix well. From different places jars spoon take portions of ground grain weighing $5 \mathrm{~g}$, weighed on analytical balances and placed in a pre-dried box and dried in an oven at $\mathrm{t}=100-105^{\circ} \mathrm{C}$ until a constant weight of the residue. Constant weight is considered to be achieved if the difference between the two weighings does not exceed $0.001 \mathrm{~g}$. The first weighing is carried out in 4-6 hours from the beginning of drying, and each subsequent - in 2 hours. Differences between re-determinations by this method are within 1\% (relative).

In order to determine the moisture content of flax seeds, it does not need to be crushed. The mass fraction of moisture is determined by the same parameters as for other grain samples (Koryakov et al., 2012).

\section{Determination of water status in the obtained extracts}

Water state in the obtained mixtures at different stages of hydration was investigated by the method of low-temperatures canning calorimetry.

To determine the state of water in the obtained extracts from flax seeds and starchy grain raw materials, thermodynamic method was used. The essence of this method is to determine the fractional composition of water, i.e. water in the bound state has other physical and chemical properties, and it has no phase of the first order transition below $273 \mathrm{~K}$.

If the system, which contains both free and bound water, is subjected to cooling and subsequent heating in the calorimeter, one can see the peaks of crystallization and melting of only free water on the corresponding thermograms.

The exothermic peak of crystallization, which corresponds to a non-equilibrium process, has the form of a ballistic curve. Therefore, the quantification of heat dissipation cannot be performed. The melting process on the thermogram is recorded in the form of a time-stretched endothermic peak or several peaks.

Since the melting process is an equilibrium process, the peak area bounded by the DSC curve and the baseline of the calorimeter is proportional to the heat of the phase transition, and accordingly to the amount of free water (Sniezhkin et al., 2011).

\section{Determination of absolute values of heat absorption}

Absolute values of heat absorption were calculated using the data obtained during calibration, where double-distilled water was used as a standard substance.

The mass of non-freezing water defined as the bound one, is the difference between the total mass of water in the samples and the mass of the freezing part:

$$
m_{n f}=m_{w}-\frac{A_{f} \cdot m_{s t} \cdot \Delta H_{s t}}{A_{s t} \cdot \Delta H_{f}}
$$


where:

$\mathrm{A}$ is the area under the melting curve; $\mathrm{m}_{2}$

$\mathrm{m}$ is mass; $\mathrm{kg}$

$\mathrm{H}$ is enthalpy of melting; $\mathrm{J} / \mathrm{kg}$

$\mathrm{r}$ is the correlation coefficient;

$\mathrm{f}$ is freezing water;

$\mathrm{nf}$ is non-freezing water;

st is a standard substance;

$\mathrm{w}$ is a total moisture.

In this case it is assumed that the enthalpy of water melting in a jelly-like mixture and water are equal (Dmytrenko et al. 2011).

\section{Result and discussion}

\section{Mass fraction of moisture}

The mass fraction of moisture in studied materials has the following meanings (Table 1):

\section{Mass fraction of moisture in studied materials}

Table 1

\begin{tabular}{|c|c|}
\hline Seed & Mass fraction of moisture, $\%$ \\
\hline Flax seeds & $6,3 \pm 0,1$ \\
\hline Amaranth seeds & $9,4 \pm 0,2$ \\
\hline Oats & $10,5 \pm 0,4$ \\
\hline Rice & $11,8 \pm 0,3$ \\
\hline
\end{tabular}

The study of the mass fraction of moisture in cereals showed that $1 / 3$ of the moisture is in the form of a solvent in the intercellular space, $2 / 3$ is bound to the polymers and are included into plant fibers and polysaccharides.

\section{Water status in the obtained flax seed extracts}

If the system, which includes both free and bound water, is subjected to cooling and subsequent heating in the calorimeter, the peaks of crystallization and melting of only free water on the corresponding thermograms can be observed (Pooria et al., 2010) (Figure 1).

Figure 1 shows specific DSC curves of heating samples of flax seed extracts. As can be seen from thethermogram, qualitative changes in the investigated samples do not occur, and they start at $-58^{\circ} \mathrm{C}$ temperature in the form of an almost straight line:

1. DSC curve (liquid part, where whey was used as a solvent), the state of almost straight line (slight voltage fluctuations) ends at $-16^{\circ} \mathrm{C}$;

2. DSC curve (machined sample, homogeneous by means of mixing, with whey as a solvent), the state of the straight line ends at $-12{ }^{\circ} \mathrm{C}$, this is the largest angle of inclination and we recorded the voltage change from 2 to $2.5 \mathrm{mV}$; 
3. DSC curve (machined sample, homogeneous, water as a solvent), the state of the straight line ends at $-16^{\circ} \mathrm{C}$.

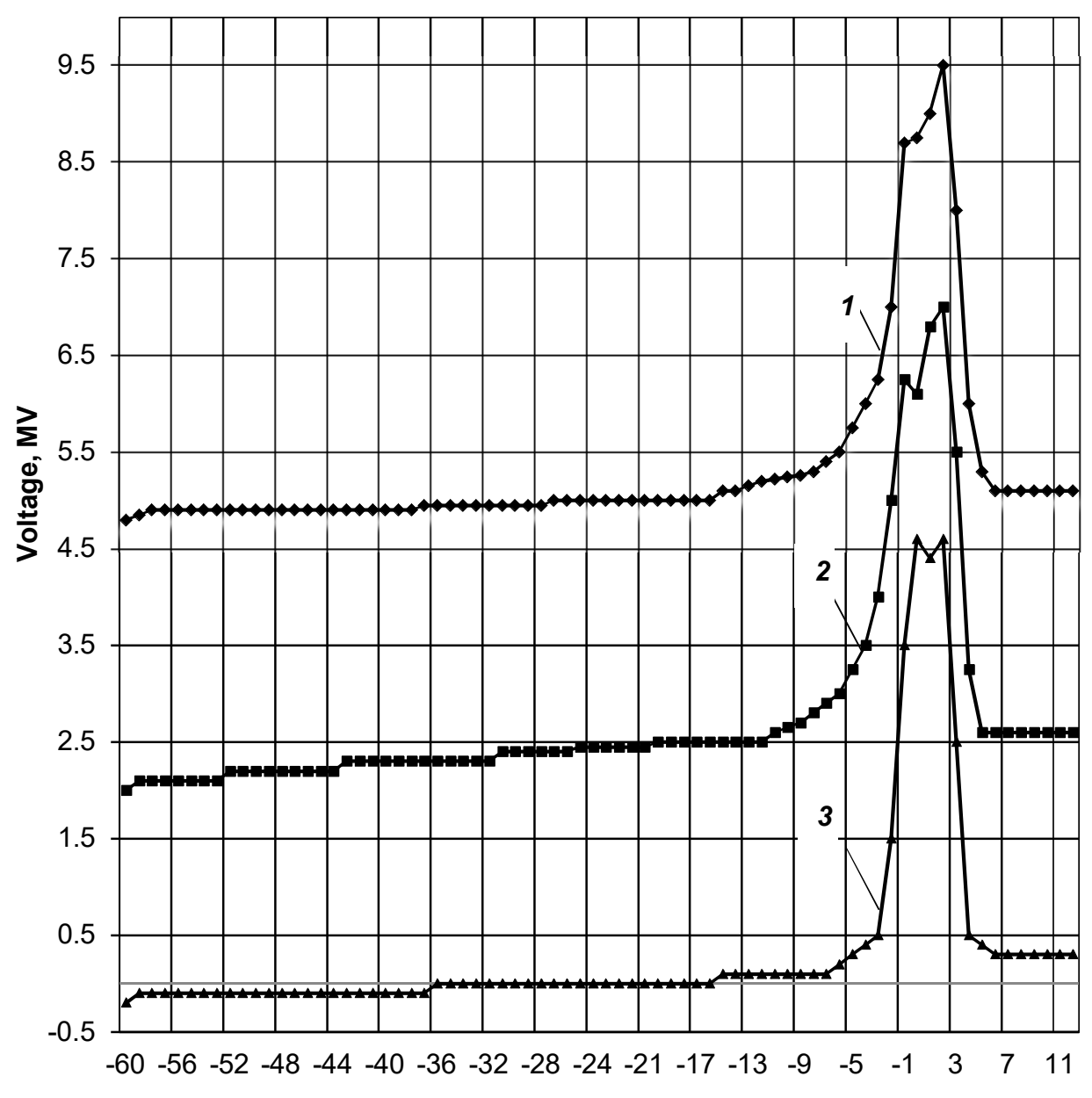

Temperature, ${ }^{\circ} \mathrm{C}$

Figure 1. DSC curves of flax seed suspension samples:

1 - sample of flax seed extract with whey after mechanical treatment (upper layer);

2 - sample of flax seed extracts with whey (suspension);

3 - sample of flax seed extract with water after mechanical treatment (upper layer).

If the suspension's cooling takes place faster than water diffusion can occur (subsequently this does not allow water to crystallize intensively), the concentrated amorphous solution has a low concentration (Pooria et al., 2010). As a result, the vitreous transition takes place at low temperature, as in the flax seeds sample $\left(-12--16{ }^{\circ} \mathrm{C}\right)$. If the 
cooling is slow, the glassy transition takes place at higher temperatures $(-2--4){ }^{\circ} \mathrm{C}$ and constant concentration (the same concentration as in grain raw materials consisting mainly of starch). Thus, it can be argued that the concentration of the amorphous solution has a constant concentration of $0.1-0.25 \mathrm{~g} / \mathrm{g}$ and below. In this case, the vitreous transition has insignificant values even in case of DSC measurements at high temperatures $\left(70{ }^{\circ} \mathrm{C}\right)$, as it is known from the scientific resource (Dmytrenko et al., 2011).

A rapid decrease in temperature during cooling of the samples leads to a sharp increase in the viscosity of cellular moisture. Thus, this leads to a decrease of moisture diffusion rate to the surface of the growing ice crystals (Pooria et al., 2010). As a result, the part of freezing water in the solution and in the capillaries of the dietary fibers is in the state of glass transition. It crystallizes only during the next slow heating. As we can see on 1 and 2 curves (whey as a solvent), the path of the curves of glassy transition is much less than on the curve 3 . It can be explained by the fact that the whey due to the presence of lactic acid accelerates the movement of moisture and therefore is subjected to the process of glassy transition. The process of moisture crystallization takes place faster on the 3 DSC curve than on the 1 and 2 DSC curves, as they used whey as a solvent.

Analysis of experimental data for flax seeds shows that in samples with water as a solvent the total moisture is $92.4 \%$, bound moisture is $3.77 \%$, and in samples with whey as a solvent it is $83.49 \%$ and $13.44 \%$ respectively. Whereas after the first stage of processing (percolation) these indicators were as follows: total moisture was $99.91 \%$ and bound moisture $-0.09 \%$. Thus, the mechanical treatment that was used to intensify the extraction and hydration processes has provided redistribution of the fractional composition of moisture in the bound water's favor. When using serum as a solvent, this redistribution is even more defined. Of course, this is influenced by the $\mathrm{pH}$ of the environment changed by the whey, but the main factor is carbohydrates, the amount of which in the whey is up to $6.0 \%$ (Dmytrenko et. al., 2011).

The obtained experimental results provide a basis for a new description of the moisture transition from the free state to the bound one by hydration during the extraction process.

\section{Water status in the obtained extracts of amaranth, oats, and rice}

According to the same scheme, the redistribution of water during hydration of grinded grain raw materials was investigated. The raw materials contained starch (amaranth seeds, oats, rice which belong to monopolysaccharides) and starch grains consist of amylose (70$80 \%$ ) and amylopectin (30-20\%). These polysaccharides contribute to the maximum swelling figures and water retention at a temperature of $60-80{ }^{\circ} \mathrm{C}$. But in order to with stand the same experimental conditions, the determination of the water state and its redistribution after treatment in the secereals was also carried out at a temperature of $25^{\circ} \mathrm{C}$, along with flax seeds, in which carbohydrates are represented by heteropolysaccharides (Mihaylik et al., 2007).

The obtained DSC curves of water melting in suspensions of all types of grain raw materials, which consist mainly of monopolysaccharides without mechanical treatment (Figure 2) have a specific shape that differs from DSC curves of melting water with mechanical treatment and differs significantly from DSC curves of heteropolysaccharides (flaxseeds) (Figure 1). 


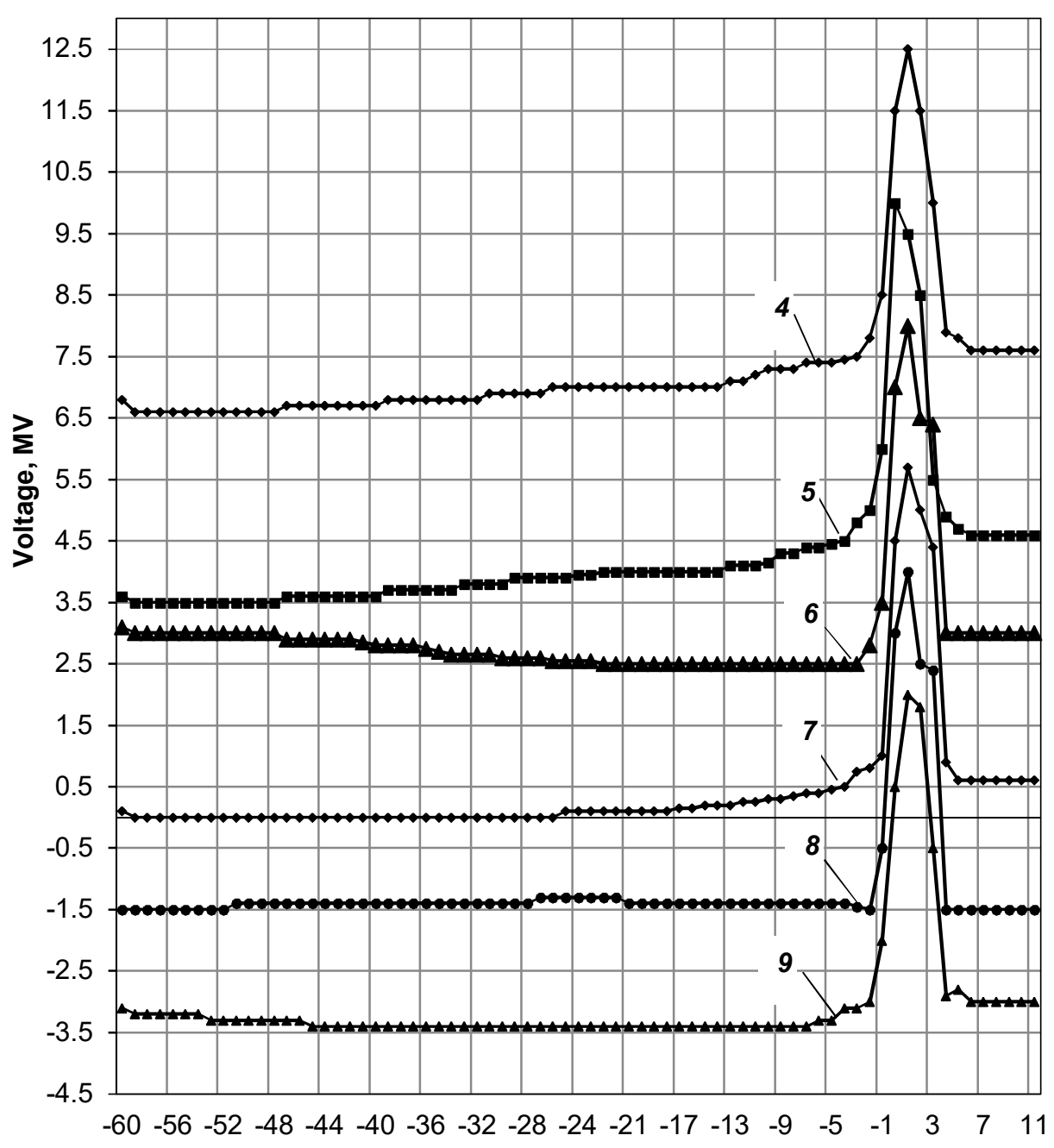

Temperature, ${ }^{\circ} \mathrm{C}$

Figure 2. DSC curves of suspensions samples of amaranth, oats, and rice seeds.

4 - suspension of amaranth in water (initial sample);

5 - suspension of amaranth in water (mechanical treatment );

6 - suspension of oats in water (initial sample);

7 - suspension of oats in water (mechanical treatment );

8 - suspension of rice in water (initial sample);

9 - suspension of rice in water (mechanical treatment ). 
The weight of freezing water in the treated sample of amaranth suspensions increased to $2.561 \mathrm{mg}$ from the weight of $2.164 \mathrm{mg}$ in the untreated sample. And the mass of bound water in the treated sample was $0.519 \mathrm{mg}$, while in the untreated sample $-0.136 \mathrm{mg}$. In the oat suspensions samples both the initial and treated peaks were almost the same; the shift towards low temperatures was not observed. In the treated sample of rice suspensions, a second small peak occurred and the total area towards the untreated sample increased. It means that the mass of freezing water in rice increased to $2.590 \mathrm{mg}$ from $2.275 \mathrm{mg}$ after treatment in the untreated sample, at the same time, the mass of bound water increased to $0.280 \mathrm{mg}$ from $0.055 \mathrm{mg}$ in the untreated sample. Analysis of the obtained experimental data showed that percentage of the total moisture in the suspension of amaranth seeds, the amount of freezing water after treatment decreased by $10.84 \%$, in oat suspension by $4.69 \%$, in rice suspension by $7.4 \%$. At the same time, the amount of bound water increased by $10.94 \%$ for the suspension of amaranth seeds, for the suspension of oats by $4.67 \%$, and for rice by $7.4 \%$ (Dmytrenko et. al., 2011).

Based on the above, it can be concluded that the mechanical treatment used to intensify the extraction and hydration processes has provided a redistribution of the fractional composition of moisture increasing content of bound moisture. However, the processes of moisture binding by monopolysaccharides, which include amaranth, oats, rice, are significantly different from the moisture binding by heteropolysaccharides (flaxseeds). Further experiments to determine the state of water and its redistribution during hydration at different environment temperatures will be planned in the future researches.

\section{Conclusions}

1. Experimentally, using the DSC method the results of determining the amount of antifreeze water in suspensions were obtained and the dynamics of its change during hydration was determined. The amount of bound water after pre-treatment with water as a solvent (infusion) was $0.09 \%$ and after mechanical treatment it was $3.77 \%$; after mechanical treatment with whey as a solvent (upper part) the amount was $11.04 \%$ and mixed homogeneous sample $13.44 \%$.

2. It was revealed that the total content of dissolved substances and moisture content can be judged by the amount of displacement of the melting peak's maximum. Thus, in the initial mixture of flax and water it is $93.5 \mathrm{~g} / \mathrm{g}_{\mathrm{d} . \mathrm{m} .}$., in machined $12.16 \mathrm{~g} / \mathrm{g}_{\mathrm{d} . \mathrm{m} \text {.; }}$ in suspensions with whey, respectively $7.53 \mathrm{~g} / \mathrm{g}_{\mathrm{d} . \mathrm{m} .}$ and $5.06 \mathrm{~g} / \mathrm{g}_{\mathrm{d} . \mathrm{m} .}$.

3. Based on the results it was proved that the applied mechanical treatment, type of the solvent and ambient temperature provide intensification of extraction and hydration processes, as well as redistribution of the fractional composition of bound water's favor.

4. The method of low-temperature DSC was used to study the content of bound water in the system of grain raw materials (amaranth seeds, oats, rice), which consists mainly of starch (water depending on the processing parameters (infusion) and mechanical treatment at a constant temperature $-25^{\circ} \mathrm{C}$ and type of solvent (water).

5. It was investigated that the content of bound water during mechanical treatment in comparison with infusion increased by 4 times for amaranth seeds, 3 times for rice, and 1.4 times for oats. 


\section{References}

Bazhai-Zhezherun S., Bereza-Kindzerska L., Tohachynska L. (2017), Vplyv roslynnykh ekstraktiv na syntez vitaminiv pid chas proroshchuvannia zerna, Proceedings of the XIV International Conference "Strategy of Quality in Industry and Education» is issued in two volumes (articles, theses), 2017, Varna, Bulgaria, 2, pp. 118-121.

Dmytrenko N. V., Dubovikova N. S., Snjezhkin Ju. F., Mykhajlyk V. A., Dekusha L. V., Vorobjov L. J. (2011), Vyvchennja vplyvu stanu vody v kharchovykh roslynnykh materialakh na teplotuvy parovuvannja, Naukovi praci Odesjkoji nacionaljnoji akademiji kharchovykh tekhnologhij, 40(2), pp. 71-75.

Ghoshal G., Kansal S.K. (2019), The emerging trends in functional and medicinal beverage research and its health implication, Functional and Medicinal Beverages, Volume 11: The Science of Beverages, pp. 41-71.

Gulevich A.L., Leshchev S.M., Rakhman'ko E.M. (2009), Ekstraktsionnye metody razdeleniya i kontsentrirovaniya veshchestv, BGhU, Minsk.

Koryakov V.I., Medvedevskikh M.Y., Medvedevskikh S.V., Parfenova E.G., Sobina E.P. (2012), Development of standard samples of mass fractions of moisture and protein in grain and grain products, Measurement Techniques, 54(10), pp. 1198-1210.

Kreisz S., Arendt E. K., Hübner F., Zarnkov M. (2008), Cereal-based gluten-free functional drinks, Food Science and Technology, pp. 373-392.

Mihaylik V.A., Dmitrenko N.V., Mihaylik T.A. (2007), Vliyanie termicheskogo vozdeystviya na sostoyanie vodyi v rastitelnyih tkanyah, Promyishlennaya Teplotehnika, 29(7), pp. 212-217.

O’Neil C.E., Nicklas T.A., Zanovec M., Cho S. (2010), Whole-Grain Consumption Is Associated with Diet Quality and Nutrient Intake in Adults: The National Health and Nutrition Examination Survey, 1999-2004, Available at: https://www.jandonline.org/article/S0002$8223 \% 2810 \% 2901191-0 /$ fulltext

Papanikolaou Y., Fulgoni V. (2017), Certaingrain foods can be meaningful contributors to nutrient density in the diets of U.S. children and adolescents: Data from the national health and nutrition examination survey, 2009-2012, Available at: https://grainfacts.com/grains-contributeshortfall-nutrients

Papanikolaou Y., Fulgoni V. (2018), Grains Contribute Shortfall Nutrients and Nutrient Density to Older US Adults: Data from the National Health and Nutrition Examination Survey, 2011-2014, Available at: https://www.ncbi.nlm.nih.gov/pmc/articles/PMC5986414/

Poutanen K., Sozer N., Della Valle G. (2014), How can technology help to deliver more of grain in cereal foods for a healthy diet?, Journal of Cereal Science, 54, pp. 327-336.

Gill P., Moghadam T.T., Ranjbar B. (2010) Differential scanning calorimetry techniques: Applications in biology and nanoscience, Journal of Biomolecular Techniques, 21(4): 167-193.

Rosa-Sibakov N., Poutanen K., Micard V. (2015), How does wheat grain, bran and aleurone structure impact their nutritional and technological properties?, Trends Food Science Technology, 41, pp. $118-134$.

Seal C.J., Courtin C.M., Venema K., de Vries J. (2021), Health benefits of whole grain: effects on dietary carbohydrate quality, the gut microbiome, and consequences of processing, Comprehensive Reviews in Food Science and Food Safety, 20, pp. 2742-2768.

Smith C., Van Haute M.J., Rose, D.J. (2020), Processing has differential effects on microbiota-accessible carbohydrates in whole grains during in vitro fermentation, Applied and Environmental Microbiology Journal, 86, pp. 105-120.

Sniezhkin Yu., Mykhailyk V., Dmytrenko N. (2011), Dynamika zminy stanu vody v parenkhimnykh tkanynakh roslyn pry sushinni, Promyslova Teplotekhnika, 33(2), pp. 35-40. 